\title{
Efeito do vento sobre a atividade de vôo de Plebeia remota (Holmberg, 1903) (Apidae, Meliponini)
}

\author{
Sergio Dias Hilário ${ }^{1,4}$, Márcia de Fátima Ribeiro² \& Vera Lucia Imperatriz-Fonseca ${ }^{3}$ \\ Biota Neotropica $v 7$ (n3) - http://www.biotaneotropica.org.br/v7n3/pt/abstract?article +bn03907032007 \\ Recebido em 20/06/07 \\ Versão Reformulada recebida em 24/10/07 \\ Publicado em 08/11/07 \\ ${ }^{1}$ Departamento de Zoologia, Instituto de Biociências, Universidade de São Paulo - USP, \\ Rua do Matão, Tr. 14, 321, Cidade Universitária, CEP 05508-900, São Paulo, SP, Brasil \\ ${ }^{2}$ Embrapa Semi-Árido, BR 428, Km 152, Zona Rural CP 23, CEP 56302-970, Petrolina, PE, Brasil \\ ${ }^{3}$ Departamento de Biologia, Faculdade de Filosofia Ciências e Letras de Ribeirão Preto, \\ Universidade de São Paulo - USP, \\ Av. Bandeirantes, 3900, Monte Alegre, CEP 14040-901, Ribeirão Preto, SP, Brasil \\ ${ }^{4}$ Autor para correspondência: Sergio Dias Hilário,e-mail: sedilar@usp.br
}

\begin{abstract}
Hilário, S.D., Ribeiro, M.F. \& Imperatriz-Fonseca, V.L. Wind effect on flight activity of Plebeia remota (Holmberg, 1903) (Apidae, Meliponini). Biota Neotrop. Sep/Dez 2007 vol. 7, no. 3 http://www.biotaneotropica. org.br/v7n3/pt/abstract?article+bn03907032007. ISSN 1676-0603.

Through an automated system, foragers' flight activity of four colonies of Plebeia remota was registered at same time from December 1998 to December 1999. The large amount of data obtained allowed a quantitative and seasonal analysis of the effect of speed and direction of wind on their flight activity. In all four seasons, the smallest flight activity of Plebeia remota occurred when there was no wind or when the wind speed average was below $0.5 \mathrm{~m} / \mathrm{s}$. The flight activity peaks occurred in higher measured wind speeds and varied according to the seasons and the colonies. In the summer, the flight activity peaks occurred between 3.5 and $5.5 \mathrm{~m} / \mathrm{s}$ of speed, in the autumn, in the series 4.0-4.5 m/s, and in the spring between 4.5 and $6.0 \mathrm{~m} / \mathrm{s}$. In the winter, clear restriction upon flight activity occurred in wind speeds above $5.5 \mathrm{~m} / \mathrm{s}$. Plebeia remota foragers guided preferentially their flights for certain wind directions. Except summer, the directions were similar to the four colonies. These directions matched with the locations where the most used floral resources are. On the other hand, lowest flights number coincided with conditions when the foragers would left their colonies upwind.
\end{abstract}

Keywords: flight activity, stingless bees, climatic factors, wind, foraging.

\section{Resumo}

Hilário, S.D., Ribeiro, M.F. \& Imperatriz-Fonseca, V.L. Efeito do vento sobre a atividade de vôo de Plebeia remota (Holmberg, 1903) (Apidae, Meliponini). Biota Neotrop. Sep/Dez 2007 vol. 7, no. 3 http://www.biotaneotropica.org.br/v7n3/pt/abstract?article+bn03907032007. ISSN 1676-0603.

Através de um sistema automatizado, a atividade do vôo de forrageiras de quatro colônias de Plebeia remota foi registrada, simultaneamente, de dezembro de 1998 a dezembro de 1999. A grande quantidade de dados obtidos permitiu uma análise quantitativa e sazonal do efeito da velocidade e direção do vento sobre a atividade de vôo. Nas quatro estações, a menor atividade de vôo de Plebeia remota ocorreu quando não houve vento ou quando a velocidade média do vento esteve abaixo de $0,5 \mathrm{~m} / \mathrm{s}$. Os picos de atividade de vôo ocorreram em velocidades de vento maiores e variaram segundo as estações e as colônias. No verão, os picos de atividade de vôo estiveram entre 3,5 e $5,5 \mathrm{~m} / \mathrm{s}$ de velocidade, no outono, na classe 4,0-4,5 m/s, e na primavera entre 4,5 e $6,0 \mathrm{~m} / \mathrm{s}$. Entretanto, no inverno, houve clara restrição da atividade externa sob velocidades de vento superiores a 5,5 m/s. As forrageiras de $P$. remota orientaram preferencialmente seus vôos para certas direções de vento. Exceto no verão, as direções predominantes de vôo foram similares entre as quatro colônias. Estas direções também coincidiram com a posição dos recursos florais mais utilizados pelas colônias. Quando as forrageiras tinham que sair da colônia com vento contra, se registrou menor atividade de vôo.

Palavras-chave: atividade de vôo, abelhas sem ferrão, fatores climáticos, vento, forrageio. 


\section{Introdução}

No vôo dos insetos, o bater das asas é freqüentemente descrito como "nadar no melado", já que o ar atmosférico é altamente viscoso para estes animais (Dudley 1999). A teoria aerodinâmica convencional mostrou-se falha para explicar como os insetos vencem a viscosidade do meio e voam (Dickinson et al. 1999, Dudley 1999). Recentemente, simulações de vôo com uma miniatura robótica de uma mosca-de-fruta, imersa em óleo mineral, permitiram a formulação de mecanismos instáveis (circulação rotacional e "wake capture"), que possibilitam o vôo de muitos insetos (Dickinson et al. 1999). Contudo, ainda se conhece muito pouco acerca da mecânica de vôo dos insetos (Taylor 2001).

Além da viscosidade do ar, outro fator que pode influenciar o vôo de insetos é o vento. Este é o mais transitório dentre os fatores climáticos, podendo permanecer constante ou oscilar rapidamente. Mesmo assim, a velocidade e a direção do vento são utilizadas em pesquisas de comportamento de vôo (Unwin 1980).

Em abelhas, a percepção do vento ocorre por meio de pêlos, que estão sobre a cabeça e os olhos, e pelo órgão de Johnston (Srinivasan et al. 1997). Nos seus clássicos estudos sobre o sistema de comunicação das abelhas melíferas, von Frisch (1967) observou que as forrageiras transmitiam distâncias maiores em suas danças, quando voavam sob vento contrário à direção de vôo (Srinivasan et al. 1997, Dyer 2002).

O vento é mencionado como um fator restritivo ao vôo de muitas espécies de abelhas, tais como: mamangavas (Michener 1974, Morse 1982), abelhas melíferas (Roubik 1989) e abelhas sem ferrão (Oliveira 1973, Iwama 1977, Kleinert-Giovannini 1982, Inoue et al. 1985, Kleinert-Giovannini \& Imperatriz-Fonseca 1986, Heard \& Hendrikz 1993, Hilário et al. 2001, Pick \& Blochtein 2002ab). Lundie (1925) verificou que a atividade de vôo de abelhas melíferas em um dia com ventos entre 16 e $21 \mathrm{mph}(7,2 \mathrm{~m} / \mathrm{s}$ e $9,4 \mathrm{~m} / \mathrm{s}$, respectivamente), foi $28,53 \%$ inferior ao movimento de um dia considerado calmo por este autor. As abelhas melíferas e as mamangavas voam mais próximas ao solo quando há vento forte, do que em condições calmas (Srinivasan et al. 1996, 1997, Riley et al. 1999, 2003, Dyer 2002). Desse modo, o efeito do vento é provavelmente similar ao efeito da chuva, fazendo com que as abelhas selecionem recursos florais mais próximos às suas colméias (Roubik 1989).

Neste estudo, investigamos como a velocidade e a direção do vento influenciam a atividade de vôo de Plebeia remota. Como se trata de uma espécie bastante pequena, a expectativa geral é de que seja muito sensível às variações na velocidade e direção do vento, com reflexos sobre sua atividade de forrageio por alimento.

\section{Material e Métodos}

Quatro colônias de Plebeia remota, duas provenientes de Prudentópolis/PR $\left(25^{\circ} 13^{\prime} \mathrm{S}\right.$ e $\left.50^{\circ} 59^{\prime} \mathrm{O}\right)$ e duas provenientes de Cunha/SP $\left(23^{\circ} 05^{\prime} \mathrm{S}\right.$ e $\left.44^{\circ} 55^{\prime} \mathrm{O}\right)$, foram estudadas no Laboratório de Abelhas em São Paulo (Instituto de Biociências, Universidade de São Paulo: $23^{\circ} 33^{\prime}$ S e $46^{\circ} 43^{\prime} \mathrm{O}$ ). Estas colônias serão mencionadas no texto como $\operatorname{Pr} 1, \operatorname{Pr} 2, \operatorname{Pr} 3$ e Pr4, respectivamente. Estudos anteriores com DNA mitocondrial e microssatélites feitos com colônias de abelhas destas mesmas procedências sugerem que estes dois grupos constituem duas unidades evolutivas independentes (Francisco 2002, Arias et al. 2003). O movimento de entrada e saída das forrageiras das colônias foi registrado com o auxílio de fotocélulas colocadas em tubos plásticos, que serviam de acesso ao ambiente externo. As colméias foram posicionadas lado a lado na bancada no interior do Laboratório, com as entradas voltadas para mesma direção. As fotocélulas foram conectadas a um computador por meio de um controlador lógico programável (PLC: programmable logic controller Möeller). Dados de atividade de vôo das abelhas em 281 dias foram registrados entre 23/12/98 e 22/12/99 e separados para análise, segundo as estações do ano. Os horários de aurora e crepúsculo foram obtidos do Observatório Naval dos Estados Unidos (http://aa.usno.navy.mil/). Estes horários delimitam o período máximo de atividade de forrageio de $P$. remota, uma abelha diurna. No total, dados de atividade de vôo de 3829 horas foram obtidos simultaneamente para as quatro colônias.

Os dados horários de velocidade média e direção do vento foram obtidos do Laboratório de Climatologia e Biogeografia (LCB), do Departamento de Geografia, FFCLH - Universidade de São Paulo. Para verificar se a relação entre estes parâmetros e outros fatores climáticos variava segundo as estações do ano, utilizamos dados climáticos (temperatura, umidade relativa, radiação solar e precipitação pluviométrica), também obtidos do LCB. Registros da pressão barométrica foram obtidos do Departamento de Ciências Atmosféricas, IAG - Universidade de São Paulo. Foto aérea do local de estudo (Figura 1) foi obtida do Laboratório de Cartografia - LABCART, do Departamento de Geografia, FFCLH, Universidade de São Paulo.

Em face das variáveis terem tido uma distribuição não-normal, todos os testes estatísticos utilizados foram de natureza não-paramétrica (Zar 1999). Com a finalidade de verificar se a velocidade média e a direção do vento foram diferentes segundo as estações do ano, realizamos testes de Kruskal-Wallis. A relação entre a velocidade média do vento e os outros fatores climáticos, segundo as estações, foi averiguada através de testes de correlação de Spearman (Zar 1999). Para analisar se a direção do vento exercia algum efeito sobre a atividade de vôo, utilizamos a estatística circular. Assim, testes de Rayleigh foram realizados para cada colônia e para cada estação do ano (Batschelet 1981, Benedito-Silva 1997, Zar 1999). Neste teste, um termo freqüientemente utilizado é acrofase, definido aqui como o ângulo médio. A acrofase é a fase, a partir de um ponto de referência, na qual há maior probabilidade de encontrar a atividade. $\mathrm{O}$ comprimento do vetor médio " $\mathrm{r}$ " indica a significância (mínimo $=0$, máximo $=1$ ) e é a medida de concentração da atividade na acrofase. O desvio angular serve como medida de dispersão (Batschelet 1981, Benedito-Silva 1997, Zar 1999).

Nos diagramas circulares, cada ponto distribuído ao redor do círculo representa 100 vôos. A posição central do topo do círculo representa a direção norte, que equivale a $0^{\circ}=360^{\circ}$. O intervalo das classes de distribuição é de $30^{\circ}$. O total de pontos por classe é o número médio de abelhas. No centro do círculo está o vetor da acrofase e a linha interna que acompanha o círculo é o desvio angular.

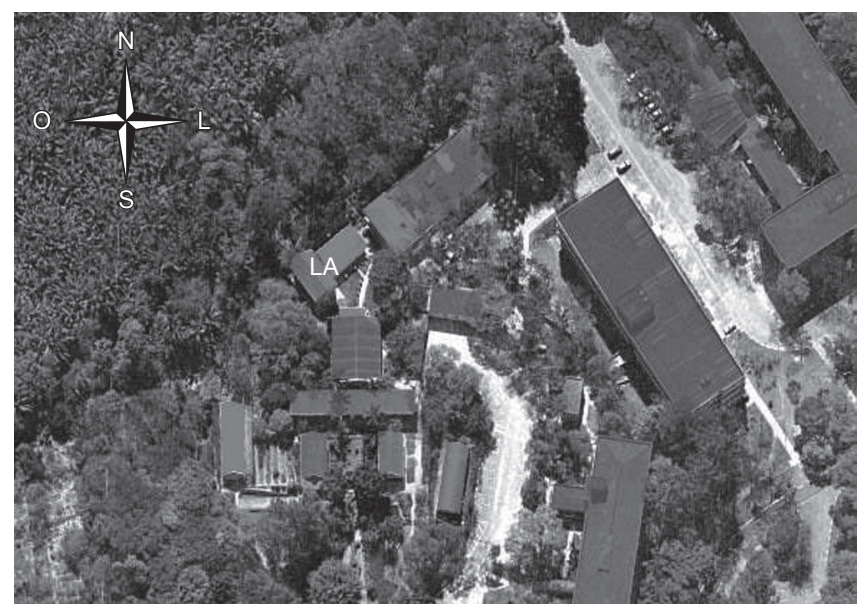

Figura 1. Foto aérea do Laboratório de Abelhas (LA) e arredores.

Figure 1. Aerial photo of the Bee Laboratory (LA) and surroundings. 
A relação entre a atividade de vôo de todas as colônias, ordenadas segundo a direção do vento, e os outros fatores climáticos, para todas as estações, foi averiguada através de testes de correlação de Spearman (Zar 1999). Os valores utilizados foram as 12 médias de atividade de vôo e de cada fator climático, uma para cada classe de distribuição de direção do vento $\left(360^{\circ}: 30^{\circ}=12\right)$.

Para comparar os valores de atividade de vôo em relação à direção do vento, obtivemos coeficientes de concordância de Kendall. Desse modo, foi possível determinar se para uma mesma estação do ano, houve similaridade na preferência entre as colônias por certas direções. Este teste serviu também para tentar discriminar respostas das colônias das duas linhagens evolutivas (provenientes de Prudentópolis - Pr1 e Pr2 e de Cunha - Pr3 e Pr4).

\section{Resultados}

Houve diferenças significativas nas velocidades médias $(H=99,4$; $\mathrm{p}=0,0001)$ e nas direções do vento $(H=36,5 ; \mathrm{p}=0,0001)$, entre as estações do ano.

\section{Velocidade do vento}

De modo geral, nas quatro estações do ano, a menor atividade de vôo (número médio de vôos) das quatro colônias de Plebeia remota ocorreu quando não houve vento ou quando a velocidade média do vento esteve abaixo de $0,5 \mathrm{~m} / \mathrm{s}$. Houve então aumento na atividade de vôo, a partir das velocidades de $0,5 \mathrm{~m} / \mathrm{s}$ e $1,5 \mathrm{~m} / \mathrm{s}$ com relativa estabilidade até cerca de $4,0 \mathrm{~m} / \mathrm{s}$ (Figuras 2 a 5; verão, outono, inverno e primavera, respectivamente). Entretanto, freqüentemente, picos de atividade de vôo ocorreram em velocidades de vento maiores, com alguma variação entre as estações do ano e entre as colônias estudadas.

No verão (Figura 2), os picos de atividade de vôo estiveram entre $4,5 \mathrm{~m} / \mathrm{s}$ e $5,5 \mathrm{~m} / \mathrm{s}$ de velocidade, para as colônias $\operatorname{Pr} 1, \operatorname{Pr} 2$ e Pr3. Neste mesmo intervalo, verificou-se queda na atividade da colônia Pr4. No outono (Figura 3), o pico de atividade ocorreu na classe 4,0-4,5 m/s de velocidade, para todas as colônias.

No inverno (Figura 4), os picos de atividade de vôo de cada colônia aconteceram em diferentes velocidades de vento e variaram mais entre as colônias, porém com clara restrição do vôo sob velocidades superiores a $5,5 \mathrm{~m} / \mathrm{s}$.

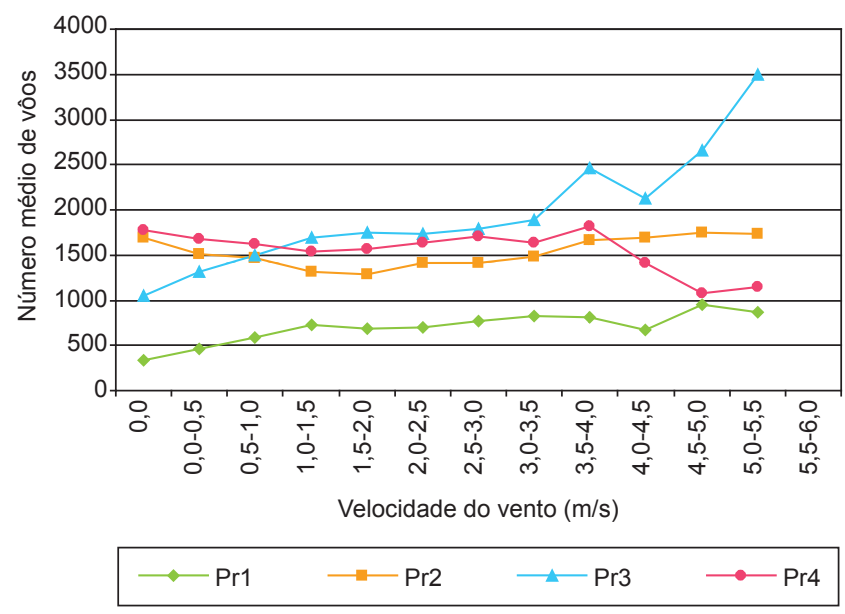

Figura 2. Atividade de vôo das quatro colônias de Plebeia remota em relação à velocidade do vento $(\mathrm{m} / \mathrm{s})$, no verão.

Figure 2. Flight activity of four Plebeia remota colonies related to the wind speed, in summer.
Na primavera (Figura 5), os picos de atividade de vôo ocorreram na classe 5,5-6,0 m/s, para as colônias $\operatorname{Pr} 2$ e $\operatorname{Pr} 4$, e na classe 4,5-5,0 m/s para a colônia $\operatorname{Pr} 3$. A atividade de vôo da colônia Pr1 foi quase constante entre $0,5 \mathrm{~m} / \mathrm{s}$ e $6,0 \mathrm{~m} / \mathrm{s}$.

Freqüentemente, as correlações de Spearman entre a velocidade do vento e outros fatores climáticos foram significativas nas quatro estações do ano, exceto nos seguintes casos: pressão barométrica no verão; temperatura no inverno e na primavera; e umidade relativa no inverno (Tabela 1).

\section{Direção do vento}

Com algumas variações, a maior atividade de vôo de P. remota ocorreu quando as direções de vento estiveram entre $330^{\circ}$ e $150^{\circ}$ (verão, Figura 6), entre $360^{\circ}$ e $150^{\circ}$ (outono, Figura 7 ; inverno, Figura 8 ) e entre $300^{\circ}$ e $90^{\circ}$ (primavera, Figura 9). A menor atividade de vôo ocorreu quando as direções de vento estiveram entre $180^{\circ}$ e $270^{\circ}$, em todas as estações do ano (Figuras 6 a 9).

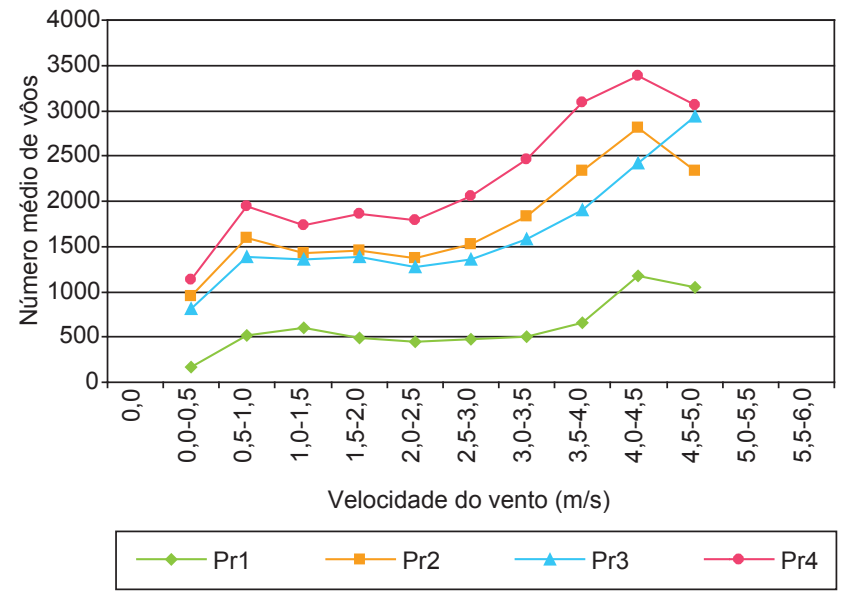

Figura 3. Atividade de vôo das quatro colônias de Plebeia remota em relação à velocidade do vento $(\mathrm{m} / \mathrm{s})$, no outono.

Figure 3. Flight activity of four Plebeia remota colonies related to the wind speed, in autumn.

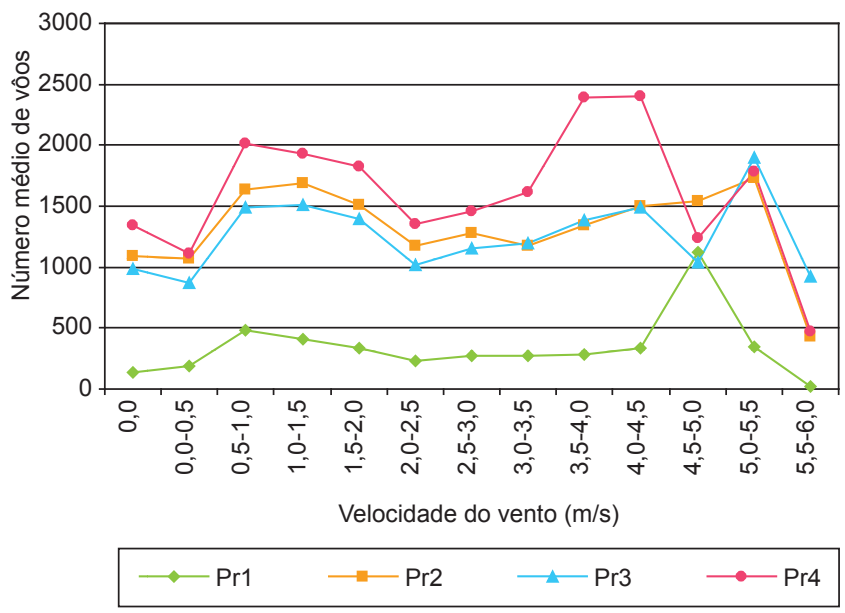

Figura 4. Atividade de vôo das quatro colônias de Plebeia remota em relação à velocidade do vento $(\mathrm{m} / \mathrm{s})$, no inverno.

Figure 4. Flight activity of four Plebeia remota colonies related to the wind speed, in winter. 
Todos os testes de Rayleigh (Tabela 2) foram estatisticamente significativos, com $\mathrm{p}<0,05$, o que mostra que as forrageiras de $P$. remota orientaram seus vôos preferencialmente para certas direções de vento. Os desvios angulares foram maiores no verão e na primavera, o que indica uma atividade de vôo mais difusa em relação à direção do vento, neste período mais quente do ano. Isto também se traduz em valores mais baixos do vetor médio, em especial no verão.

A atividade de vôo de todas as colônias, ordenadas segundo a direção do vento, foi correlacionada significativamente com a radiação nas quatro estações do ano (Tabela 3). Outras correlações significativas entre a atividade de vôo e outros fatores climáticos ocorreram: umidade relativa (verão, cols. Pr3 e Pr4; inverno, col. Pr1), precipitação (outono, todas as colônias) e pressão barométrica (primavera, cols. Pr2 e Pr3). Na primavera, a atividade de vôo de todas as colônias foi correlacionada também com a temperatura e com a umidade relativa.

No outono, inverno e primavera, a freqüência com que os vôos foram orientados para as diferentes direções foi similar entre as colônias. No verão houve similaridade apenas entre as colônias $\operatorname{Pr} 3$ e Pr4 (Tabela 4). Portanto, as forrageiras das colônias de Prudentópolis e de Cunha não divergiram em suas preferências por certas direções de vento.

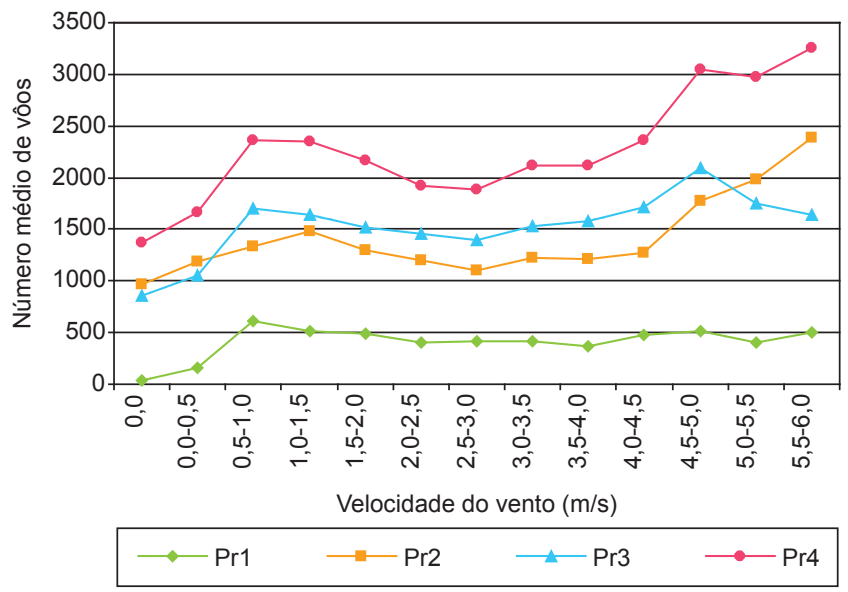

Figura 5. Atividade de vôo das quatro colônias de Plebeia remota em relação à velocidade do vento $(\mathrm{m} / \mathrm{s})$, na primavera.

Figure 5. Flight activity of four Plebeia remota colonies related to the wind speed, in spring.

\section{Discussão}

Embora forrageiras de Plebeia remota voem a velocidades de vento superiores a $5,5 \mathrm{~m} / \mathrm{s}$ no inverno e na primavera, estes ventos impõem fortes restrições sob temperaturas mais baixas no inverno.

Entre espécies de abelhas sociais com maior tamanho, a influência da velocidade do vento sobre a atividade de vôo é bastante variável. Bombus cessa o forrageamento apenas quando o vento excede $14,0 \mathrm{~m} / \mathrm{s}$, mas também foi relatada a interrupção de forrageio a $8,0 \mathrm{~m} / \mathrm{s}$ sob condições mais frias (Morse 1982). As enormes Bombus são capazes de manter a atividade de vôo sob condições menos favoráveis de clima (mais vento, por ex.) para as demais abelhas (Michener 1974). Em Apis, observaram-se limiares de velocidade de vento entre

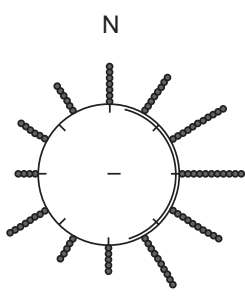

$\operatorname{Pr} 1$

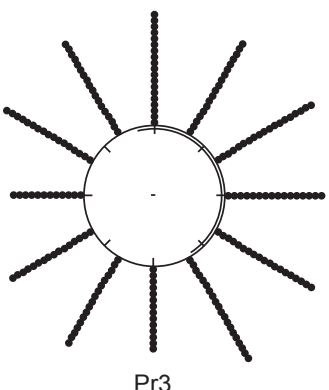

$\operatorname{Pr} 3$

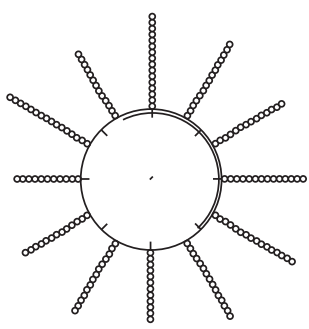

Pr2

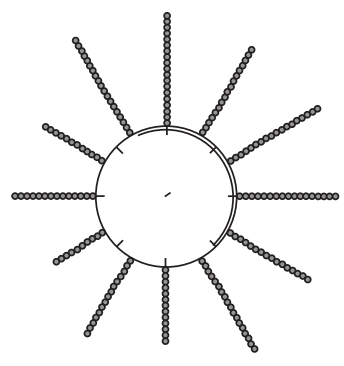

Pr4
Figura 6. Distribuição espacial da atividade de vôo das forrageiras das quatro colônias de Plebeia remota em relação à direção do vento (graus), no verão. A direção norte é indicada pela letra N. Cada ponto distribuído ao redor do circulo representa 100 vôos.

Figure 6. Spatial distribution of flight activity of foragers of four Plebeia remota colonies related to wind direction (degrees), in summer. North direction is indicated by the "N". Each point around the circle represents 100 flights.

Tabela 1. Coeficientes de correlação de Spearman $\left(r_{s}\right)$ entre a velocidade do vento e outros fatores climáticos (temperatura do ar, umidade relativa do ar, pressão barométrica, radiação solar e precipitação pluviométrica), para as estações do ano. O valor da probabilidade (p), em negrito, indica que a correlação foi significativa.

Table 1. Spearman correlation coefficients ( $\mathrm{r}$ ) between wind speed and other climatic factors (air temperature, relative humidity, barometric pressure, solar radiation and precipitation), for all seasons. The probability value (p), in bold print, indicates that the correlation was significant.

\begin{tabular}{lrrrrrrrr}
\hline \multirow{2}{*}{ Fatores climáticos } & \multicolumn{2}{c}{ Verão } & \multicolumn{2}{c}{ Outono } & \multicolumn{2}{c}{ Inverno } & \multicolumn{2}{c}{ Primavera } \\
\cline { 2 - 8 } & $\mathbf{r}_{\mathbf{s}}$ & $\mathbf{p}$ & $\mathbf{r}_{\mathrm{s}}$ & $\mathbf{P}$ & $\mathbf{R}_{\mathrm{s}}$ & $\mathbf{p}$ & $\mathbf{r}_{\mathrm{s}}$ & $\mathbf{p}$ \\
\hline Temperatura & 0,275 & $\mathbf{0 , 0 0 0 1}$ & 0,124 & $\mathbf{0 , 0 0 0 1}$ & $-0,013$ & 0,6636 & $-0,023$ & 0,4788 \\
Umidade relativa & $-0,355$ & $\mathbf{0 , 0 0 0 1}$ & $-0,182$ & $\mathbf{0 , 0 0 0 1}$ & $-0,031$ & 0,3031 & $-0,200$ & $\mathbf{0 , 0 0 0 1}$ \\
Pressão barométrica & 0,016 & 0,6259 & 0,234 & $\mathbf{0 , 0 0 0 1}$ & 0,242 & $\mathbf{0 , 0 0 0 1}$ & 0,310 & $\mathbf{0 , 0 0 0 1}$ \\
Radiação solar & 0,343 & $\mathbf{0 , 0 0 0 1}$ & 0,245 & $\mathbf{0 , 0 0 0 1}$ & 0,226 & $\mathbf{0 , 0 0 0 1}$ & 0,237 & $\mathbf{0 , 0 0 0 1}$ \\
Precipitação pluviométrica & $-0,165$ & $\mathbf{0 , 0 0 0 1}$ & $-0,166$ & $\mathbf{0 , 0 0 0 1}$ & 0,080 & $\mathbf{0 , 0 0 9 4}$ & $-0,149$ & $\mathbf{0 , 0 0 0 1}$ \\
\hline
\end{tabular}




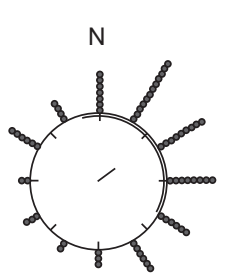

$\operatorname{Pr} 1$

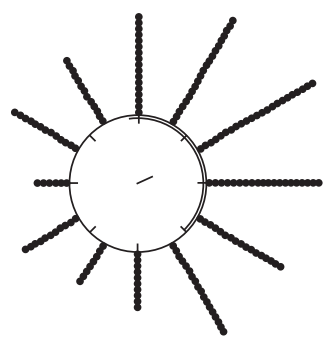

Pr3
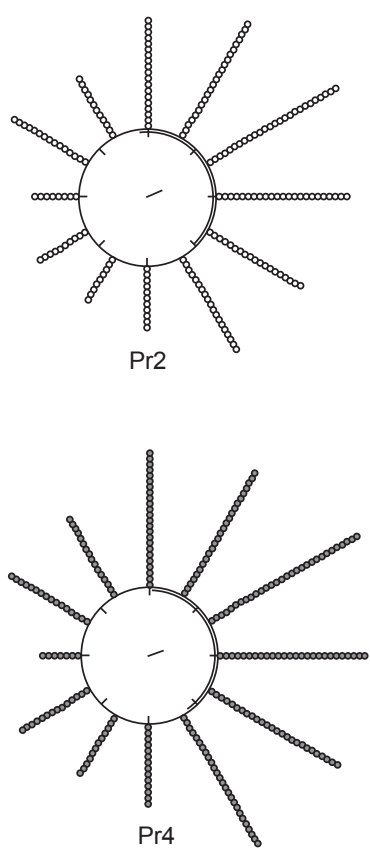

Figura 7. Distribuição espacial da atividade de vôo das forrageiras das quatro colônias de Plebeia remota em relação à direção do vento (graus), no outono. A direção norte é indicada pela letra N. Cada ponto distribuído ao redor do circulo representa 100 vôos.

Figure 7. Spatial distribution of flight activity of foragers of four Plebeia remota colonies related to wind direction (degrees), in autumn. North direction is indicated by the "N". Each point around the circle represents 100 flights.

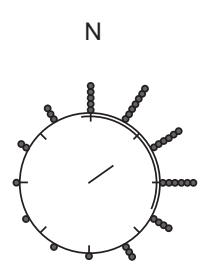

$\operatorname{Pr} 1$

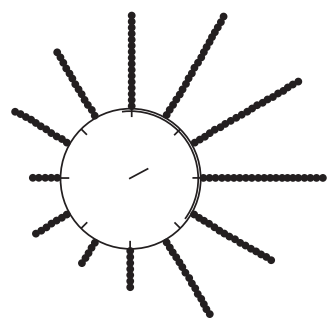

Pr3

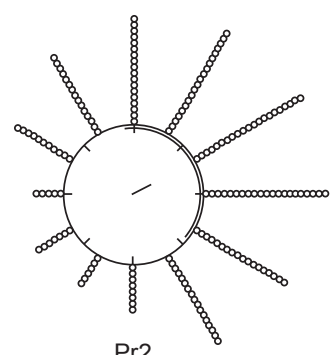

$\operatorname{Pr} 2$

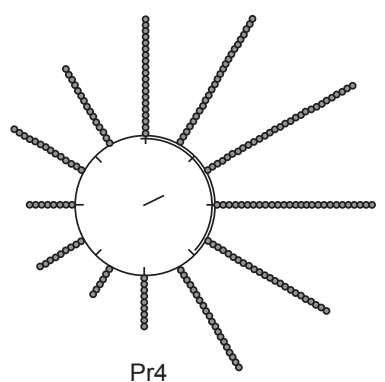

Pr4
Figura 8. Distribuição espacial da atividade de vôo das forrageiras das quatro colônias de Plebeia remota em relação à direção do vento (graus), no inverno. A direção norte é indicada pela letra N. Cada ponto distribuído ao redor do circulo representa 100 vôos.

Figure 8. Spatial distribution of flight activity of foragers of four Plebeia remota colonies related to wind direction (degrees), in winter. North direction is indicated by the "N". Each point around the circle represents 100 flights.

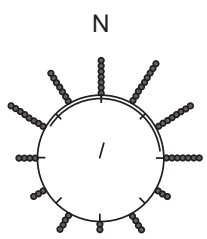

$\operatorname{Pr} 1$

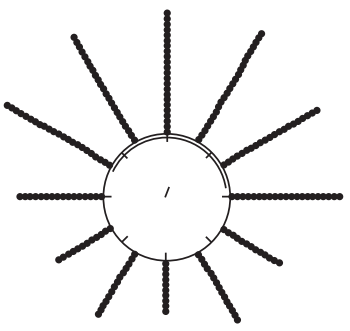

Pr3

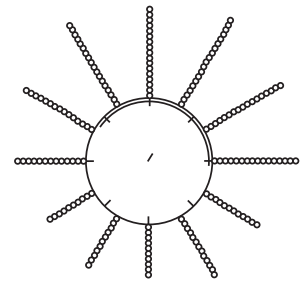

Pr2

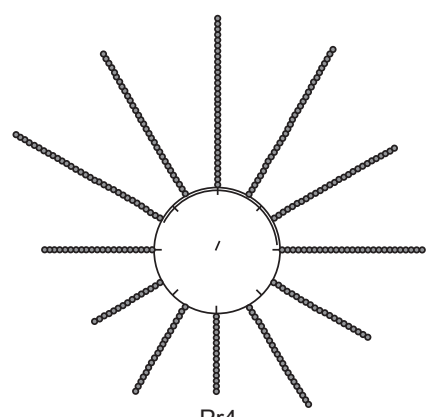

$\operatorname{Pr} 4$
Figura 9. Distribuição espacial da atividade de vôo das forrageiras das quatro colônias de Plebeia remota em relação à direção do vento (graus), na primavera. A direção norte é indicada pela letra N. Cada ponto distribuído ao redor do circulo representa 100 vôos.

Figure 9. Spatial distribution of flight activity of foragers of four Plebeia remota colonies related to wind direction (degrees), in spring. North direction is indicated by the "N". Each point around the circle represents 100 flights.

4,5 m/s e 9,4 m/s (Lundie 1925, Roubik 1989), dependendo também da temperatura.

O tamanho da abelha deve ser importante em seu deslocamento contra o vento, pois abelhas maiores podem controlar melhor seus movimentos. Assim, não é surpresa que o limiar superior de velocidade de vento para Bombus seja mais alto do que para Apis, e de que este seja maior do que os limiares das pequenas abelhas sem ferrão. Apis e Bombus são capazes de compensar com maior eficiência o vento lateral durante o vôo (Riley et al. 1999, 2003), mas é impossível voar contra o vento cuja velocidade excede a velocidade de vôo do inseto (Mikkola 1986). Freqüientemente, o deslocamento de insetos menores do que $1,5 \mathrm{~cm}$ é controlado por processos atmosféricos (Farrow 1986).

As abelhas sem ferrão têm porte pequeno, em geral menor do que $0,8 \mathrm{~cm}$, e por isso se mostram mais sensíveis ao vento. KleinertGiovannini \& Imperatriz-Fonseca (1986) observaram ligeiro decréscimo da atividade de vôo de Melipona marginata marginata e $M$. m. obscurior quando as velocidades de vento atingiram $3,0 \mathrm{~m} / \mathrm{s}$. A exposição prolongada aos ventos a essa velocidade, causou a interrupção da atividade de vôo de ambas subespécies. Entretanto, Borges \& Blochtein (2005) observaram atividade de vôo de $M$. m. obscurior entre $0,0 \mathrm{~m} / \mathrm{s}$ e $10,3 \mathrm{~m} / \mathrm{s}$, na primavera-verão, e entre $0,0 \mathrm{~m} / \mathrm{s}$ e 4,0, no outono-inverno, portanto com clara influência de outras variáveis climáticas, em particular a temperatura ambiental.

Heard \& Hendrikz (1993) não observaram restrição da atividade de vôo de Trigona carbonaria, sob ventos de até $2,4 \mathrm{~m} / \mathrm{s}$. Iwama (1977) verificou que velocidades de vento de $2,0 \mathrm{~m} / \mathrm{s}$ a $4,0 \mathrm{~m} / \mathrm{s}$ não restringiram a atividade de vôo da minúscula Tetragonisca angustula.

O gênero Plebeia é composto por abelhas muito pequenas $(<0,6 \mathrm{~cm})$, por exemplo, as forrageiras de $P$. remota pesam 
Tabela 2. Acrofases da orientação de vôo das forrageiras de quatro colônias de Plebeia remota, por estação.

Table 2. Acrophases of the flight orientation of Plebeia remota foragers, in four colonies and for all seasons.

\begin{tabular}{|c|c|c|c|c|}
\hline \multirow[t]{2}{*}{ Estações } & \multicolumn{4}{|c|}{ Colônias } \\
\hline & Pr1 & $\operatorname{Pr} 2$ & Pr3 & Pr4 \\
\hline \multicolumn{5}{|l|}{ Verão } \\
\hline Número de vôos & 9013 & 16710 & 20586 & 18783 \\
\hline Acrofase (graus) & $90,1^{\circ}$ & $50,2^{\circ}$ & $66,1^{\circ}$ & $55,2^{\circ}$ \\
\hline Desvio Angular (graus) & $73,3^{\circ}$ & $79,3^{\circ}$ & $78,7^{\circ}$ & $77,2^{\circ}$ \\
\hline Vetor Médio & 0,181 & 0,042 & 0,058 & 0,092 \\
\hline Significância estatística & S & S & $\mathrm{S}$ & S \\
\hline \multicolumn{5}{|l|}{ Outono } \\
\hline Número de vôos & 6647 & 19289 & 17433 & 23576 \\
\hline Acrofase (graus) & $53,0^{\circ}$ & $65,6^{\circ}$ & $63,9^{\circ}$ & $73,7^{\circ}$ \\
\hline Desvio Angular (graus) & $66,4^{\circ}$ & $70,3^{\circ}$ & $71,0^{\circ}$ & $71,0^{\circ}$ \\
\hline Vetor Médio & 0,329 & 0,247 & 0,232 & 0,233 \\
\hline Significância estatística & $\mathrm{S}$ & $\mathrm{S}$ & $\mathrm{S}$ & $\mathrm{S}$ \\
\hline \multicolumn{5}{|l|}{ Inverno } \\
\hline Número de vôos & 3888 & 16754 & 15534 & 20671 \\
\hline Acrofase (graus) & $53,5^{\circ}$ & $59,6^{\circ}$ & $59,0^{\circ}$ & $64,6^{\circ}$ \\
\hline Desvio Angular (graus) & $60,3^{\circ}$ & $68,1^{\circ}$ & $67,5^{\circ}$ & $67,5^{\circ}$ \\
\hline Vetor Médio & 0,445 & 0,294 & 0,305 & 0,306 \\
\hline Significância estatística & S & $\mathrm{S}$ & $\mathrm{S}$ & $\mathrm{S}$ \\
\hline \multicolumn{5}{|l|}{ Primavera } \\
\hline Número de vôos & 6589 & 17034 & 21455 & 29274 \\
\hline Acrofase (graus) & $13,2^{\circ}$ & $21,0^{\circ}$ & $7,9^{\circ}$ & $11,0^{\circ}$ \\
\hline Desvio Angular (graus) & $69,9^{\circ}$ & $75,3^{\circ}$ & $73,6^{\circ}$ & $73,9^{\circ}$ \\
\hline Vetor Médio & 0,255 & 0,136 & 0,175 & 0,169 \\
\hline Significância estatística & $\mathrm{S}$ & $\mathrm{S}$ & $\mathrm{S}$ & $\mathrm{S}$ \\
\hline
\end{tabular}

Acrofases obtidas em graus $\left(0^{\circ}=\right.$ Norte $)$. Significância das acrofases obtidas pelo teste de Rayleigh $(\mathrm{p}<0,05)$.

Acrophases given in degrees $\left(0^{\circ}=\right.$ North $)$. Acrophase significance given by the Rayleigh test ( $\mathrm{p}$ value $<0.05) . \mathrm{S}=$ significant.

$8,4 \pm 1,0$ mg (Hilário \& Imperatriz-Fonseca 2002) e medem cerca de $0,5 \mathrm{~cm}$ de comprimento e, por isso, devem ser bastante afetadas mesmo por ventos de velocidade moderada $(5,0 \mathrm{~m} / \mathrm{s}$ ou $18 \mathrm{~km} / \mathrm{h})$. Oliveira (1973) observou que a atividade de vôo de $P$. droryana e $P$. saiqui foram afetadas por velocidades de vento acima de $3,0 \mathrm{~m} / \mathrm{s}$ $(10,8 \mathrm{~km} / \mathrm{h})$ e cessaram a partir de 5,0 m/s (18,0 km/h). Pick \& Blochtein $(2002 \mathrm{a}, \mathrm{b})$ analisaram a atividade de vôo de $P$. saiqui em ampla faixa de velocidades de vento $(0,0 \mathrm{~m} / \mathrm{s}$ a $9,0 \mathrm{~m} / \mathrm{s})$, constando forte restrição sob velocidades acima de 6,0 m/s. Kleinert-Giovannini (1982) também notou que colônias fracas (em população) de $P$. emerina foram mais afetadas pelo vento do que colônias fortes, sendo que as últimas interrompiam a atividade de vôo com ventos de 4,0 m/s.

A direção do vento também influencia a atividade de vôo das forrageiras de $P$. remota. Menores atividades de vôo aconteceram quando o vento soprava em sentido contrário ao deslocamento da forrageira para fora da colônia. Ou seja, é muito provável que as forrageiras escolham voar principalmente a favor do vento.

Quando um inseto está voando a favor do vento, também se torna difícil saber se seu sentido é determinado apenas pelo próprio vento, ou se está relacionado com predisposições inatas ou questões relativas à economia de forrageio (Mikkola 1986). De qualquer modo, a maior atividade de vôo de $P$. remota ocorreu com vento a favor, cujas direções também conduziam as forrageiras às plantas mais atrativas para a espécie, nesta localidade: Archontophoenix cunninghamiana, Eucalyptus spp., Cecropia sp., Piptadenia sp., Tipuana speciosa e Mimosa daleoides, cuja distribuição espacial pode ser observada em Ramalho et al. (1985) e comparada com a foto aérea (Figura 1). Essas fontes florais são árvores que exigem o forrageio bem acima do nível do solo e, portanto, mais exposto aos ventos. Este quadro sugere que o acesso das forrageiras de $P$. remota à copa das árvores deve ser favorecido pelo vento a favor. De fato, na Mata Atlântica, as abelhas sem ferrão, inclusive $P$. remota, são mais abundantes nas flores do dossel (Ramalho 2004).

O vôo mais alto e distante do solo parece ser favorecido pelo vento a favor, em espécies robustas de Bombus. Mesmo com controle mais eficiente de vôo, essas grandes forrageiras mantêm-me mais próximas ao solo quando há vento contra o sentido do deslocamento (Riley et al. 1999). Roubik (1989) também relata que as abelhas de grande porte mantinham-se próximas ao solo quando forrageavam sob condições adversas de vento, enquanto as pequenas abelhas sem ferrão aderiam-se às inflorescências, reiniciando o vôo apenas quando o vento diminuía. Insetos mais próximos do solo podem controlar melhor seu vôo, já que sua velocidade ali é maior do que a velocidade do vento (Farrow 1986).

Ish-Am \& Eisikowitch (1998) observaram que as forrageiras de Apis mellifera tenderam a voar contra o vento, entre abacateiros, e que esta tendência aumentou com a velocidade do vento. Mas Apis é bem maior do que $P$. remota e pode ter controle mais preciso de vôo. Além disso, nos deslocamentos curtos e de orientação para pouso nas flores, o vôo contra o vento pode ser favorecido. Já nos grandes deslocamentos entre a colônia e flores, certamente mudam as restrições básicas do vento sobre a orientação espacial e sobre a economia de forrageio (Mikkola 1986).

O vôo a favor do vento pode ter razões estritamente econômicas: por exemplo, as forrageiras de Apis mellifera demoram menos tempo para alcançar fontes de xarope, quando voam a favor do vento (Srinivasan et al. 1996, 1997). Segundo Roubik (1989), "one means of increasing flight speed and avoiding increased heat production would be to maintain a downwind flight direction". Assim, a mesma direção de vento a favor que auxiliaria os vôos de longa distância das forrageiras de $P$. remota até as principais fontes de alimento, acima referidas, também dificultaria o retorno das mesmas para as colônias. Usando informação pessoal de Roubik, Ish-Am \& Eisikowitch (1998) relatam que as abelhas preferem forragear contra o vento, quando sem carga de alimento, e a favor do vento quando retornam carregadas para as colônias. Esta certamente não é uma descrição adequada para o comportamento geral de $P$. remota que, além disso, evita com mais frequiência deixar a colônia com ventos contra a arremetida de vôo.

$\mathrm{O}$ vôo contra o vento pode ser a maneira mais efetiva para localizar fontes de alimento através do odor das flores (Ish-Am \& Eisikowitch 1998, Wenner 1998, 2002), principalmente quando este é o estímulo básico na troca de informação entre forrageiras na colméia, como provavelmente acontece nas espécies de Plebeia (Lindauer \& Kerr 1960, Kerr \& Esch 1965, Michener 1974, Nieh 2004). Assim, a constatação de que os vôos predominam na direção do vento, sugere que, freqüentemente, $P$. remota não estaria usando o odor como indicação de direção a longas distâncias.

Além do vento, é inegável a influência direta ou indireta de outros fatores climáticos e ecológicos, inclusive a posição espacial das fontes florais em relação às colônias de $P$. remota. Certamente, as abelhas utilizam muitas informações na atividade de forrageio (Biesmeijer et al. 1998, Biesmeijer \& Slaa 2004), assim a escolha ou fidelidade de $P$. remota a determinados recursos (Ramalho et al. 1985, Ramalho 2004) provavelmente modulam a predisposição para o vôo a favor do vento. Apesar de ser possível demonstrar a influência da direção 
Tabela 3. Coeficientes de correlação de Spearman $\left(\mathrm{r}_{\mathrm{s}}\right.$ ) entre as médias da atividade de vôo das colônias Pr1 a Pr4 e os fatores climáticos (temperatura do ar, umidade relativa do ar, pressão barométrica, radiação solar, precipitação pluviométrica e velocidade do vento), ordenados segundo as direções de vento, para as estações do ano. O valor da probabilidade (p), em negrito, indica que a correlação foi significativa.

Table 3. Spearman correlation coefficients $\left(r_{\mathrm{s}}\right)$ between means of flight activity of Plebeia remota foragers and climatic factors (air temperature, relative humidity, barometric pressure, solar radiation, precipitation and wind speed), arranged according to the wind directions, in four colonies (Pr1 to Pr4) and for all seasons. The probability value (p), in bold print, indicates that the correlation was significant.

\begin{tabular}{|c|c|c|c|c|c|c|c|c|}
\hline \multirow{2}{*}{$\begin{array}{c}\text { Colônia Pr1 } \\
\text { Fatores climáticos } \\
\end{array}$} & \multicolumn{2}{|c|}{ Verão } & \multicolumn{2}{|c|}{ Outono } & \multicolumn{2}{|c|}{ Inverno } & \multicolumn{2}{|c|}{ Primavera } \\
\hline & $\mathbf{r}_{\mathrm{s}}$ & $\mathbf{p}$ & $\mathbf{r}_{\mathrm{s}}$ & $\mathbf{p}$ & $\mathbf{r}_{\mathrm{s}}$ & $\mathbf{p}$ & $\mathbf{r}_{\mathrm{s}}$ & $\mathbf{p}$ \\
\hline Temperatura & $-0,028$ & 0,931 & 0,315 & 0,319 & 0,448 & 0,145 & 0,783 & 0,003 \\
\hline Umidade relativa & $-0,406$ & 0,191 & $-0,385$ & 0,217 & $-0,594$ & 0,042 & $-0,748$ & 0,005 \\
\hline Pressão barométrica & 0,210 & 0,513 & 0,084 & 0,795 & $-0,224$ & 0,484 & $-0,573$ & 0,051 \\
\hline Radiação solar & 0,636 & 0,026 & 0,895 & 0,001 & 0,916 & 0,001 & 0,748 & 0,005 \\
\hline Precipitação & $-0,189$ & 0,557 & $-0,658$ & $\mathbf{0 , 0 2 0}$ & $-0,187$ & 0,561 & 0,053 & 0,871 \\
\hline Velocidade do vento & 0,133 & 0,681 & 0,084 & 0,795 & $-0,084$ & 0,795 & $-0,252$ & 0,430 \\
\hline Colônia Pr2 & \multicolumn{2}{|c|}{ Verão } & \multicolumn{2}{|c|}{ Outono } & \multicolumn{2}{|c|}{ Inverno } & \multicolumn{2}{|c|}{ Primavera } \\
\hline Fatores climáticos & $\mathbf{r}_{\mathrm{s}}$ & $\mathbf{p}$ & $\mathbf{r}_{\mathrm{s}}$ & p & $\mathbf{r}_{\mathrm{s}}$ & $\mathbf{p}$ & $\mathbf{r}_{\mathrm{s}}$ & p \\
\hline Temperatura & 0,203 & 0,527 & 0,182 & 0,572 & 0,385 & 0,217 & 0,769 & 0,003 \\
\hline Umidade relativa & $-0,503$ & 0,095 & $-0,315$ & 0,319 & $-0,552$ & 0,063 & $-0,909$ & 0,001 \\
\hline Pressão barométrica & 0,098 & 0,762 & 0,287 & 0,366 & $-0,098$ & 0,762 & $-0,580$ & 0,048 \\
\hline Radiação solar & 0,692 & 0,013 & 0,958 & 0,001 & 0,958 & 0,001 & 0,797 & 0,002 \\
\hline Precipitação & $-0,427$ & 0,167 & $-0,676$ & 0,016 & $-0,162$ & 0,614 & $-0,042$ & 0,897 \\
\hline Velocidade do vento & 0,378 & 0,226 & 0,140 & 0,665 & $-0,091$ & 0,779 & $-0,035$ & 0,914 \\
\hline Colônia Pr3 & \multicolumn{2}{|c|}{ Verão } & \multicolumn{2}{|c|}{ Outono } & \multicolumn{2}{|c|}{ Inverno } & \multicolumn{2}{|c|}{ Primavera } \\
\hline Fatores climáticos & $\mathbf{r}_{\mathrm{s}}$ & $\mathbf{p}$ & $\mathbf{r}_{\mathrm{s}}$ & p & $\mathbf{r}_{\mathrm{s}}$ & $\mathbf{p}$ & $\mathbf{r}_{\mathrm{s}}$ & p \\
\hline Temperatura & 0,252 & 0,430 & 0,301 & 0,342 & 0,378 & 0,226 & 0,846 & 0,001 \\
\hline Umidade relativa & $-0,839$ & 0,001 & $-0,364$ & 0,245 & $-0,552$ & 0,063 & $-0,867$ & 0,001 \\
\hline Pressão barométrica & 0,273 & 0,391 & 0,175 & 0,587 & $-0,063$ & 0,846 & $-0,671$ & $\mathbf{0 , 0 1 7}$ \\
\hline Radiação solar & 0,944 & 0,001 & 0,923 & 0,001 & 0,958 & 0,001 & 0,692 & 0,013 \\
\hline Precipitação & $-0,301$ & 0,342 & $-0,680$ & 0,015 & $-0,109$ & 0,735 & 0,014 & 0,966 \\
\hline Velocidade do vento & 0,259 & 0,417 & 0,098 & 0,762 & $-0,119$ & 0,713 & $-0,133$ & 0,681 \\
\hline Colônia Pr4 & \multicolumn{2}{|c|}{ Verão } & \multicolumn{2}{|c|}{ Outono } & \multicolumn{2}{|c|}{ Inverno } & \multicolumn{2}{|c|}{ Primavera } \\
\hline Fatores climáticos & $\mathbf{r}_{\mathrm{s}}$ & p & $\mathbf{r}_{\mathrm{s}}$ & $\mathbf{p}$ & $\mathbf{r}_{\mathrm{s}}$ & p & $\mathbf{r}_{\mathrm{s}}$ & $\mathbf{p}$ \\
\hline Temperatura & 0,483 & 0,112 & 0,119 & 0,713 & 0,364 & 0,245 & 0,790 & 0,002 \\
\hline Umidade relativa & $-0,937$ & 0,001 & $-0,280$ & 0,379 & $-0,531$ & 0,075 & $-0,937$ & 0,001 \\
\hline Pressão barométrica & 0,182 & 0,572 & 0,364 & 0,245 & $-0,035$ & 0,914 & $-0,552$ & 0,063 \\
\hline Radiação solar & 0,790 & 0,002 & 0,958 & 0,001 & 0,944 & 0,001 & 0,832 & 0,001 \\
\hline Precipitação & $-0,035$ & 0,914 & $-0,669$ & $\mathbf{0 , 0 1 7}$ & $-0,183$ & 0,568 & $-0,228$ & 0,477 \\
\hline Velocidade do vento & $-0,056$ & 0,863 & 0,245 & 0,443 & $-0,133$ & 0,681 & 0,035 & 0,914 \\
\hline
\end{tabular}

Tabela 4. Coeficientes de concordância de Kendall $(W)$ entre os pares de colônias de Plebeia remota, para as estações do ano. O valor da probabilidade (p), em negrito, indica que o teste foi significativo, havendo semelhança entre os pares.

Table 4. Kendall concordance coefficients $(W)$ between different pairs of Plebeia remota colonies, for all seasons. The probability value (p), in bold print, indicates that the concordance was significant, i.e., colonies were similar.

\begin{tabular}{cccccccccccccc}
\hline $\begin{array}{c}\text { Estações } \\
\text { Comparações }\end{array}$ & \multicolumn{3}{c}{ Verão } & \multicolumn{3}{c}{ Outono } & \multicolumn{3}{c}{ Inverno } & \multicolumn{3}{c}{ Primavera } \\
\cline { 2 - 11 } & $\mathbf{W}$ & $\mathbf{X}^{\mathbf{2}}$ & $\mathbf{P}$ & $\mathbf{W}$ & $\mathbf{X}^{\mathbf{2}}$ & $\mathbf{P}$ & $\mathbf{W}$ & $\mathbf{X}^{\mathbf{2}}$ & $\mathbf{p}$ & $\mathbf{W}$ & $\mathbf{X}^{\mathbf{2}}$ & $\mathbf{p}$ \\
\hline 1 vs. 2 & 0,74 & 16,385 & 0,127 & 0,98 & 21,462 & $\mathbf{0 , 0 2 9}$ & 0,99 & 21,692 & $\mathbf{0 , 0 2 7}$ & 0,94 & 20,769 & $\mathbf{0 , 0 3 6}$ \\
1 vs. 3 & 0,83 & 18,154 & 0,078 & 0,99 & 21,692 & $\mathbf{0 , 0 2 7}$ & 0,98 & 21,538 & $\mathbf{0 , 0 2 8}$ & 0,97 & 21,385 & $\mathbf{0 , 0 3 0}$ \\
1 vs. 4 & 0,66 & 14,615 & 0,201 & 0,94 & 20,615 & $\mathbf{0 , 0 3 8}$ & 0,98 & 21,462 & $\mathbf{0 , 0 2 9}$ & 0,95 & 21,000 & $\mathbf{0 , 0 3 3}$ \\
2 vs. 3 & 0,88 & 19,462 & 0,053 & 0,98 & 21,615 & $\mathbf{0 , 0 2 8}$ & 0,99 & 21,846 & $\mathbf{0 , 0 2 6}$ & 0,96 & 21,077 & $\mathbf{0 , 0 3 3}$ \\
2 vs. 4 & 0,69 & 15,154 & 0,176 & 0,98 & 21,615 & $\mathbf{0 , 0 2 8}$ & 0,98 & 21,615 & $\mathbf{0 , 0 2 8}$ & 0,97 & 21,308 & $\mathbf{0 , 0 3 0}$ \\
3 vs. 4 & 0,90 & 19,692 & $\mathbf{0 , 0 5 0}$ & 0,97 & 21,231 & $\mathbf{0 , 0 3 1}$ & 0,99 & 21,846 & $\mathbf{0 , 0 2 6}$ & 0,98 & 21,538 & $\mathbf{0 , 0 2 8}$ \\
\hline
\end{tabular}


e velocidade do vento sobre o forrageio de Plebeia remota, somente com a miniaturização de transponders, poderemos dimensionar os efeitos isolados do vento sobre o vôo.

\section{Agradecimentos}

Os autores agradecem à doutoranda Denise de Araújo Alves, à Dra. Marilda Cortopassi-Laurino e aos dois referees anônimos por seus valiosos comentários e sugestões. Nós também agradecemos pelo apoio financeiro provido pelo CNPq (140169/2000-8 ao SDH e 522121/97 à VLIF).

\section{Referências Bibliográficas}

ARIAS, M.C., FRANCISCO, F.O. \& SILVESTRE, D. 2003. O DNA mitocondrial em estudos populacionais e evolutivos de meliponíneos. In Apoidea Neotropica (G.A.R. Mello \& I. Alves-dos-Santos, eds.). Universidade do Extremo Sul Catarinense, Criciúma, p. 305-309.

BATSCHELET, E. 1981. Circular Statistics in Biology. Academic Press Inc., London.

BENEDITO-SILVA, A.A. 1997. Aspectos metodológicos da cronobiologia. In Cronobiologia: Princípios e Aplicações (N. Marques \& L. Menna-Barreto, orgs.). Editora da Universidade de São Paulo, São Paulo, p. 215-238.

BIESMEIJER, J.C. \& SLAA, E.J. 2004. Information flow and organization of stingless bee foraging. Apidologie 35:143-157.

BIESMEIJER, J.C., NIEUWSTADT, M.G.L. van, LUKACS, S. \& SOMMEIJER, M.J. 1998. The role of internal and external information in foraging decisions of Melipona workers (Hymenoptera: Meliponinae). Behav. Ecol. Sociobiol. 42:107-116.

BORGES, F. VON B. \& BLOCHTEIN, B. 2005. Atividades externas de Melipona marginata obscurior Moure (Hymenoptera, Apidae), em distintas épocas do ano, em São Francisco de Paula, Rio Grande do Sul, Brasil. Rev. Bras. Zool. 22:680-686.

DICKINSON, M.H., LEHMANN, F.O. \& SANE, S.P. 1999. Wing rotation and the aerodynamics basis of insect flight. Science 284:1954-1960.

DUDLEY, R. 1999. Unsteady aerodynamics. Science 284:1937-1939.

DYER, F.C. 2002. The biology of the dance language. Annu. Rev. Entomol. 47:917-949.

FARROW, R.A. 1986. Interactions between synoptic scale and boundary-layer meteorology on micro-insect migration. In Insect Flight: Dispersal and Migration (W. Danthanarayana, ed.). Springer-Verlag, Berlin, p. 185-195.

FRANCISCO, F.O. 2002. Diversidade genética de populações da abelha sem ferrão Plebeia remota: análise do DNA mitocondrial e microssatélites. Dissertação de Mestrado, Universidade de São Paulo, São Paulo.

HEARD, T.A. \& HENDRIKZ, J.K. 1993. Factors influencing flight activity of colonies of the stingless bee Trigona carbonaria (Hymenoptera, Apidae). Aust. J. Zool. 41:343-353.

HILÁRIO, S.D. \& IMPERATRIZ-FONSECA, V.L. 2002. Seasonality influence on flight activity of Plebeia pugnax Moure (in litt.) (Hymenoptera, Apinae, Meliponini). Naturalia 27:115-123.

HILÁRIO, S.D., IMPERATRIZ-FONSECA, V.L. \& KLEINERT, A. DE M.P. 2001. Responses to climatic factors by foragers of Plebeia pugnax Moure (in litt.) (Apidae, Meliponinae). Rev. Bras. Biol. 61:191-196.

INOUE, T., SALMAH, S., ABBAS, I. \& YUSUF, E. 1985. Foraging behavior of individual workers and foraging dynamics of colonies of three Sumatran stingless bees. Res. Popul. Ecol. 27:373-392.

ISH-AM, G. \& EISIKOWITCH, D. 1998. Mobility of honey bees (Apidae, Apis mellifera L.) during foraging in avocado orchads. Apidologie 29:209-219.

IWAMA, S. 1977. A influência dos fatores climáticos na atividade externa de Tetragonisca angustula (Apidae, Meliponinae). Bol. Zool. Univ. S. Paulo 2:189-201.

KERR, W.E. \& ESCH, H. 1965. Comunicação entre as abelhas sociais brasileiras e sua contribuição para o entendimento da sua evolução. Cien. Cult. 17:529-538.
KLEINERT-GIOVANNINI, A. 1982. The influence of climatic factors on flight activity of Plebeia emerina Friese (Hymenoptera, Apidae, Meliponinae) in winter. Rev. Bras. Entomol. 26:1-13.

KLEINERT-GIOVANNINI, A. \& IMPERATRIZ-FONSECA, V.L. 1986. Flight activity and responses to climatic conditions of two subspecies of Melipona marginata Lepeletier (Apidae, Meliponinae). J. Apic. Res. 25:3-8.

LINDAUER, M. \& KERR, W.E. 1960. Communication between the workers of stingless bees. Bee World 41:29-41;65-71.

LUNDIE, A.E. 1925. The flight activities of the honeybee. USDA Dept. Bul. 1328:1-37.

MICHENER, C.D. 1974. The Social Behavior of the Bees: A Comparative Study. The Belknap Press of Harvard University Press, Cambridge.

MIKKOLA, K. 1986. Direction of insect migrations in relation to the wind. In Insect Flight: Dispersal and Migration (W. Danthanarayana, ed.). Springer-Verlag, Berlin, p. 152-171.

MORSE, D.H. 1982. Behavior and ecology of bumble bees. In Social Insects (H.R. Hermann, ed.). Academic Press Inc., New York, v.3, p. 245-322.

NIEH, J.C. 2004. Recruitment communication in stingless bees (Hymenoptera, Apidae, Meliponini). Apidologie 35:159-182.

OLIVEIRA, M.A.C. 1973. Algumas observações sobre a atividade externa de Plebeia saiqui e Plebeia droryana. Dissertação de Mestrado, Universidade de São Paulo, São Paulo.

PICK, R.A. \& BLOCHTEIN, B. 2002a. Atividades de coleta e origem floral do pólen armazenado em colônias de Plebeia saiqui (Holmberg) (Hymenoptera, Apidae, Meliponinae) no sul do Brasil. Rev. Bras. Zool. 19:289-300.

PICK, R.A. \& BLOCHTEIN, B. 2002b. Atividades de vôo de Plebeia saiqui (Holmberg) (Hymenoptera, Apidae, Meliponini) durante o período de postura da rainha e em diapausa. Rev. Bras. Zool. 19:827-839.

RAMALHO, M. 2004. Stingless bees and mass flowering trees in the canopy of Atlantic Forest: a tight relationship. Acta Bot. Bras. 18:37-47.

RAMALHO, M., IMPERATRIZ-FONSECA, V.L., KLEINERT-GIOVANNINI, A. \& CORTOPASSI-LAURINO, M. 1985. Exploitation of floral resources by Plebeia remota Holmberg (Apidae, Meliponinae). Apidologie 16:307-330.

RILEY, J.R., REYNOLDS, D.R., SMITH, A.D., EDWARDS, A.S., OSBORNE, J.L., WILLIAMS, I.H. \& MCCARTNEY, H.A. 1999. Compensation for wind drift by bumble-bees. Nature 400:126.

RILEY, J.R., GREGGERS, U., SMITH, A.D., STACH, S., REYNOLDS, D.R., STOLLHOFF, N., BRANDT, R., SCHAUPP, F. \& MENZEL, R. 2003. The automatic pilot of honeybees. P. Roy. Soc. Lond. B Bio. 270:2421-2424.

ROUBIK, D.W. 1989. Ecology and Natural History of Tropical Bees. Cambridge University Press, New York.

SRINIVASAN, M.V., ZHANG, S.W. \& BIDWELL, N.J. 1997. Visually mediated odometry in honeybees. J. Exp. Biol. 200:2513-2522.

SRINIVASAN, M.V., ZHANG, S.W., LEHRER, M. \& COLLETT, T.S. 1996. Honeybee navigation en route to the goal: visual flight control and odometry. J. Exp. Biol. 199:237-244.

TAYLOR, G.K. 2001. Mechanics and aerodynamics of insect flight control. Biol. Rev. 76:449-471.

UNWIN, D.M. 1980. Microclimate Measurement for Ecologists. Academic Press Inc., Orlando.

VON FRISCH, K. 1967. The Dance Language and Orientation of Bees. Harvard University Press, Cambridge.

WENNER, A.M. 1998. Odors, wind and colony foraging - Part II of three parts: The role of wind direction. Am.Bee J. 138:807-810.

WENNER, A.M. 2002. The elusive honey bee dance "language" hypothesis. J. Insect Behav. 15:859-878.

ZAR, J.H. 1999. Biostatistical Analysis. 4 ed. Prentice-Hall, Upper Saddle River. 